\title{
INFORMATION
}

\section{SURFACTANTS IN BRICK PRODUCTION}

\author{
E. V. Klevakina ${ }^{1}$
}

Translated from Steklo i Keramika, No. 4, p. 58, April, 2013.

The main directions of technical progress in the ceramic construction materials industry are the development of new and improvement of existing technological processes ensuring minimum consumption of energy, materials and labor resources, wide adoption of low- and no-waste technologies and the use of production byproducts.

In ceramic brick production the molding properties of clay are the most important properties. The rheological properties of clay pastes can be regulated by introducing organic-mineral process additives of the Litoplast $\mathrm{M}$ and Poliplast TD series, manufactured by the Polyplast Company. The additive and the amount added are determined individually for each production process, since the mineralogical composition and the dispersity of the raw material can differ significantly from one to another.

The structural-mechanical properties of ceramic brick largely depend on ion exchange, characteristic for clay minerals. The addition of additives based on sodium polymethylene-bis-naphthalenesulfonate and complexes of inorganic modifiers to clayey raw material gives the maximum increase of the electrokinetic potential of the particles and the wetting effect, and the electrostatic repulsion between particles, owing to a large extent to the modifiers and the action of structural forces, predominantly due to the chemical structure of the additive containing bulk aromatic rings with well solvated functional groups, manifests most fully. This gives aggregative stability to the system at high concentrations of the disperse phase.

Thus, the use of process additives from the series Lopast $\mathrm{M}$ and Poliplast TD in the production of ceramic articles, including brick, gives the following:

1) improved rheological properties of the batch;

2) higher strength characteristics, greater freeze resistance and improved exterior appearance of the finished product;

\footnotetext{
1 Poliplast-UralSib Company, Pervoural'sk, Russia.
}

3) lower wear of the main process equipment;

4) improved performance of the process equipment;

5) lower energy consumption in the production process.

The effectiveness of the process additives largely depends on the type and granulometric composition of the raw material used and other factors. It is known that clay deposits differ from one another with respect to the chemical and mineralogical composition. In brick plants, aside from clays, additional raw materials are used in order to improve the physical-mechanical properties of the finished articles.

In this connection the Poliplast Company has created a division for technical tracing of production, where trained specialists will provide assistance in choosing the required additives as well as perform laboratory and commercial tests under the customer's production conditions.

The scientific-technical center at the Poliplast Company includes accredited chemical and construction laboratories equipped with the required equipment, which makes it possible to perform tests to determine the required recipes and amounts of the corresponding additives. This makes it possible to develop additives for each batch individually.

At the present time the products of the Poliplast Company are used in brick plants in Sverdlovsk Oblast', the Republic of Kazakhstan and Perm'skii Krai. Series Litoplast M and Poliplast TD additives are being actively adopted in the production of brick in the Republic of Tatarstan, Bashkortostan, Udmurtiya, Chelyabinsk Oblast' and elsewhere.

The company's service policy makes it possible to continually improve the quality of the ready product and to develop innovative materials for the ceramic articles market and for other industries. As a result the Poliplast Company leads the market for specialized complex additives throughout the Russian Federation. 